\title{
Review on non-enzymatic electrochemical glucose sensor of hybrid nanostructure materials
}

\author{
Jemal Kassim Ebrahim * \\ Department of Chemistry, Madda Walabu University, Robe-Bale, Ethiopia.
}

Magna Scientia Advanced Research and Reviews, 2021, 01(02), 001-017

Publication history: Received on 20 November 2020; revised on 16 December 2020; accepted on 18 December 2020

Article DOI: https://doi.org/10.30574/msarr.2021.1.2.0028

\begin{abstract}
This review made on the progress of five years non-enzymatic electrochemical sensing of glucose. Following a brief discussion of the merits and limitations of enzymatic glucose sensors, we discuss the history of unraveling the mechanism of direct oxidation of glucose and theories of non-enzymatic electro-catalysis. And also we discussed nonenzymatic glucose electrodes based on the use of the metals (platinum, gold, nickel, copper, of alloys and bimetals, of carbon material), and of metal-metal oxides and some electrochemical techniques which are used to analyze different real samples according to their techniques of analysis as well a show of different sensors are produce signals from the analyte of interest.
\end{abstract}

Keywords: Glucose; Non-enzymatic Sensing; Electrochemical Sensing; Electrocatalysis

\section{Introduction}

Biosensors are attracting attention in recent years. These sensors are in using for many decades in several fields of study. Particularly, clinical inspection, environmental assessment, battery technology and different industrial applications are fundamental one. They are also classes of electrochemical sensors which are needed fewer chemicals, smaller sample volume and few pretreatments for fabrication. Many studies also examined clinical diagnosis, including detection of L-lactate, glucose, other biomaterials or combinations of biomaterials via these sensors. In recent years including glucose sensor biosensors are the most important and very essential devices in the day-to-day clinical applications, environmental monitoring, and many fields of studies [59].

Among numerous reports glucose oxidase (GOx) has widely used to construct various amperometric sensor, due to its high sensitivity and selectivity to glucose. A majority of glucose biosensors is based on the enzymatic sensors, because of their simplicity, relatively low-cost, and high-sensitivity. However, the greatest drawback of enzymatic sensors is their lack of stability due to the intrinsic nature of enzymes. To overcome the above problems, lately a number of studies have been carried out to develop non-enzymatic glucose sensors based on transition metal oxides with high sensitivity, high reproducibility, high selectivity, low detection limit, good stability and low cost, such as $\mathrm{NiO}, \mathrm{ZnO}_{2} \mathrm{CoO}, \mathrm{MnO}_{2}$, and $\mathrm{CuO}$. But, most of these compounds electrodes have their own disadvantages like poor sensitivity and low selectivity, which leads them to cause the surface poisoning of adsorbed intermediates and chloride, which greatly limits their applications [26].

Therefore, the development of a cost-effective, highly selective, fast and reliable non-enzymatic glucose sensor is still greatly stipulated or demanded in various fields. In order to full fill such gab transitional metal oxides sensors are the one which are most selective. Among the transition metal oxides, copper oxide $(\mathrm{CuO})$ is a p-type semiconductor with a

\footnotetext{
${ }^{*}$ Corresponding author: Jemal kassim

Department of Chemistry, Maddawalabu University, Bale Robe, Ethiopia.
}

Copyright (C) 2021 Author(s) retain the copyright of this article. This article is published under the terms of the Creative Commons Attribution Liscense 4.0. 
narrow-band gap of $1.2 \mathrm{eV}$ has been extensively studied because of its numerous applications in many fields of studies such as catalysis, semiconductors, batteries, gas sensors, biosensors, solar cells, magnetic storage media for electromagnetic substances and field transistors. Further, the nanostructures of $\mathrm{CuO}$ (copper oxide) exhibit a high specific surface area, good electrochemical activity, and the possibility of promoting electron transfer reactions at a lower over-potential [37].

On the other hand, zinc oxide ( $\mathrm{ZnO}$ ) has become one of the most important semiconductor materials used for various applications such as, optics, optoelectronics, sensors, and actuators due to their semiconducting, piezoelectric and pyroelectric properties. A well-aligned $\mathrm{ZnO}$ nanorods array with a large specific surface area, higher electron conductivity and many active sites, low-cost and long-term stability has attracted extensive interest applications for photocatalysis, light-emitting diodes (LEDs), Dye sensitized solar cells and sensors. Recently, ZnO nanostructures have considerable attention for the biosensors applications due to the following advantages; biocompatibility, high surface area to volume ratios, chemical stability, facile preparation, low-cost, non-toxicity, bio-safety, fast electron transfer rates, enhanced electrochemical response and increased sensitivity. In addition to this $\mathrm{ZnO}$ has a high iso-electric point (IEP) of about 9.5, which makes it suitable for the absorption of protein with low IEPs (GOx $=4.2$ ), as the protein immobilization is primarily driven by the electrostatic interaction [16].

Recently, hybrid nano-structured materials with a high surface area; good conductivity and permeability have been considered to be one of the most significant functional materials for the various emerging research fields, such as, sensor, energy conversion and environmental remediation. But, the performance of these hybrid nano structured materials mainly depends on their size, morphology, composition, structure, crystal phases and crystal appearance. Therefore, the controlled synthesis of hybrid metal oxide nanostructures is of considerable interest to achieve the required size, morphology and structure of the hybrid nanostructure. To the best of our knowledge, there are very few reports on the $\mathrm{CuO} / \mathrm{ZnO}$ nano composites for the non-enzymatic glucose sensing applications [17]. In this regard, first time they have reported, a superficial, low temperature and cost effective synthesis method in the preparation of $\mathrm{CuO}$ nano sheet/ZnO NRs hierarchical nanostructure on $\mathrm{Cu}$ substrate for the non-enzymatic glucose sensor applications. The formation of this highly active $\mathrm{CuO}$ nano leaf /ZnO NRs hierarchical structure could serve as a promising electrode material for the enhancing non-enzymatic glucose sensing due to their high surface area and electrical conductivity.

Over the past decade the development of non-enzymatic glucose sensors has risen at a considerable rate. The fabrication of a wide variety of nano-materials has introduced a plethora of selective and highly responsive glucose sensors [54]. Specially, in the area of clinical diagnostic treatment of human illness is becoming a more sophisticated science, with self-testing becoming increasingly more compact and accurate, and continuous glucose monitoring now obtained from practical commercial sensors. Glucose sensors are therefore a highly active area of sensor research, and accordingly they account for approximately $85 \%$ of the biosensor industry. Sensitive and selective glucose sensors are not only relevant for use in blood sugar monitoring, but also in the food industry, bio-processing and in the development of renewable, sustainable fuel cells. Non-enzymatic glucose electrodes used in direct oxidation show considerably greater sensitivity, with oxidation currents as high as $\mathrm{mA} \mathrm{mM}-1 \mathrm{~cm}^{-2}$ now being studied by different researchers in different research area as reported by numerous reporters. However, the superior selectivity and relative non-toxicity of enzyme based electrodes has retained the focus of commercially available glucose sensors on enzymatic systems.

In 2005, Park and his coauthors [36] firstly published an excellent and authoritative review regarding the development of non-enzymatic glucose sensors. Recently, Compton's group also published an integrated review to introduce the progress made up to now. Some other groups provided other sensors to detect glucose, including an optical glucose sensor [46]. Research into this area of sensing is evidently in full force, and in this review we hope to assess the current situation with respect to the practical application of non-enzymatic glucose sensors note. In 2008 two extensive critical reviews of enzymatic electrochemical glucose sensors were published by [17, 51]. As such, enzymatic systems will be briefly discussed herein, but the reader is encouraged to read the latter two reviews for more substantial understanding and detail.

\section{Literature review}

\subsubsection{Classification of Sensors}

One ways of sensor classification is based on output signals from the analyte. On the other hand, sensors can be broadly classified in to two categories. These are chemical sensors and electrochemical biosensors [15]. 


\subsubsection{Chemical Sensors}

Chemical sensors are small devices used for direct measurement of a physical quantity of an analyte in a sample surrounding substance (matrix) in order to obtain continuous and reversible response from the analyte of interest. Sensors (detectors/transducers) covers a wide category of devices used to monitor, measure, test, analyse data as generated due to changes in a measured norm (usually concentration for chemical sensors). In this regard, Electrochemical sensors have a wide range of advantages over the others sensors due to their electrodes can be sense the materials which are present within the host without damaging the host system and produces an electrical signal which is related to the concentration of the analyte under analysis[4].

\subsubsection{Electrochemical Sensor}

Electrochemical Sensor is a small device used for direct measurement of a physical quantity of an analyte in a sample matrix. Electrochemical sensor consists of a transduction element covered by a recognition layer which may be chemical or biological materials. The recognition layer interacts with target analyte, and then transduction element translates the chemical changes into electrical signals. Therefore, electrochemical sensor produces an electrical signal that is related to the concentration of an analyte. Electrochemical sensor produces an electrical signal that is related to the concentration of an analyte but in biosensor biological recognition processes are converted into quantitative amperometric or potentiometric response [10].

\subsubsection{Biosensors}

A biosensor contains a gratitude layers which combines a biological components such as enzymes, tissue, microorganism, nucleic acid, cellular structure etc. The interaction between analyte and biosensor molecules produce signal from the analyte of interest into detectable signal such as light, voltage, current, mass, etc. The combination of enzymatic reactions with the electrochemical method of monitoring electro active enzymatic products allowed to develop enzyme based electrochemical biosensor for sensitive and rapid determination of different samples under analysis. Biosensors have attractive applications in human care, food industry, controlling the environment and for genetic applications. The greatest advantage of such biosensors are in their application being user friendly, having a fast response, high sensitivity, strong selectivity and their practical use for real sample analysis [27].

\subsection{Enzymatic Glucose Electrochemical Sensors}

There is no doubt that the development of an ideal glucose sensor must be a top issue for the biosensor industry. Numerous processes and methodologies have been developed to create new glucose biosensors such as electrochemical methods [51], Colorimetry [34], Conductometry [33], optical methods [32], and fluorescent spectroscopy [38].

Among them, the electrochemical glucose sensors have attracted the most attention over the last 40 years because of their victorious sensitivity and selectivity. Additionally, electrochemical techniques show lower detection limits, faster response times, better long term stability and inexpensiveness. The first generation of glucose biosensors was prepared by the catalytic principle of the natural mediator (i.e. oxygen).

The consumption of oxygen was followed by electrochemical reduction at a platinum electrode. The cell current is proportional to the oxygen concentration and the current is measured (amperometric method of detection has been employed). The concentration of glucose is then proportional to the increase in current (oxygen concentration). Other than measuring the oxygen concentration, two other methods can also use to measure the glucose concentration: measuring the acid (gluconic acid) production with a pH sensor or measuring the production of $\mathrm{H}_{2} \mathrm{O}_{2}$ with a peroxide sensor. The routine use of a first-generation was hindered by two major limitations. The first limitation originates from the fact that the amperometric monitoring of hydrogen peroxide requires high operating potential. The second stems from the restricted solubility of oxygen in biological fluids that limits the enzymatic reaction, especially in the case of implantable glucose biosensors suitable for in vivo measurements [28]. With the second-generation glucose biosensors the manmade mediators were doped into the enzyme membrane, which can decrease the interference of ambient oxygen [48].

The improvements were achieved by replacing oxygen with a non-physiological electron acceptor, called redox mediator, which was able to carry electrons from the enzyme to the surface of the working electrode [28]. Using redox mediators, the measurements became insensitive to oxygen fluctuations and can be carried out at lower, more negative potentials. Organic and Organometallic redox compounds have been used as electron mediators. The third generation of glucose biosensors involves direct electron transfer between the enzyme and the electrode without mediators. Using new electrode materials, such as organic conducting salt and conducting organic substances, the electrode can perform direct electron transfer. 
The modification of glucose oxidase with an appropriate electron relay has been successfully employed to the electrode with a long chain polymer having a dense array of electron relays, which is flexible enough to fold along the enzyme structure. Ultimately, this third generation of glucose biosensors would lead to implantable, needle-type devices for continuous in vivo monitoring of blood glucose [11]. Such devices would offer improved control of diabetes in connection with an internal insulin release system. However, so far its full potential has not been reached.

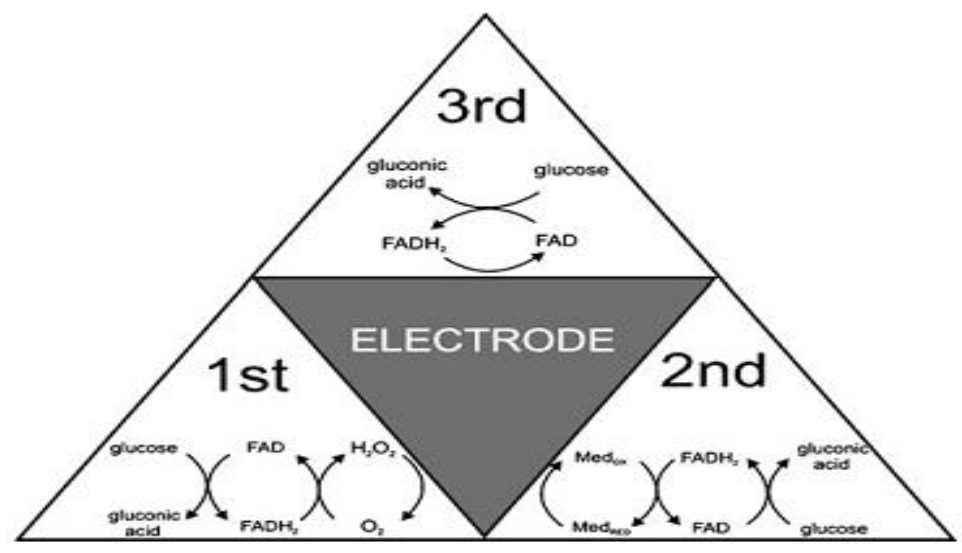

Figure 1 Summary of enzymatic glucose oxidation mechanisms, presented as first, second and third-generation sensors.

\subsubsection{First Generation Enzymatic Glucose Sensors}

First generation glucose biosensors are dependent on the presence of oxygen as a co-substrate to ensure the catalytic regeneration of the FAD centre. This can be illustrated in the following chemical reaction equation.

$\mathrm{GOx}(\mathrm{FADH} 2)+\mathrm{O} 2 \longrightarrow \mathrm{GOx}(\mathrm{FAD})+\mathrm{H} 2 \mathrm{O} 2$

First generation glucose electrodes face two major problems; these are presence of electroactive interference species in the blood and the dependence on free oxygen as a catalytic mediator. The former problem, in short the potential range at which hydrogen peroxide is oxidized coincides with the oxidation potential of numerous compounds found in blood. The oxygen dependence of first generation enzyme glucose sensors is a problem specific to this generation. The errors surrounding this high dependence on oxygen to mediate regeneration of the catalytic centre are quite significant, as oxygen levels can vary considerably. There is an oxygen limitation in which there is quite simply not enough oxygen available in a real blood sample to efficiently maintain glucose oxidation, thus this oxygen deficit has a great impact on accurate determination of glucose levels.

\subsubsection{Second Generation Enzymatic Glucose Sensors}

Due to the major problem of oxygen dependence observed in first generation enzymatic glucose sensors, the use of alternative co-substrates was introduced. That is, synthetic, electron-accepting mediators are utilized to facilitate electron transfer, with their consequent re-oxidation by the electrode resulting in a quantifiable amperometric current. These mediators possess a number of essential characteristic that idealize them for enzymatic glucose analysis. These, include a low molecular weight and insoluble nature so as to effectively diffuse without complexing, a reversible or quasireversible properties, a suitably lower redox potential to avoid oxidation of interfering species, a high stability and resistance to forming side compounds, and a low toxicity [49]

\section{$2.3 \quad$ Modified Electrodes}

Electrodes usually modify with surface active layers such as conductive polymers, inorganic oxides or hybrid materials in the area of electrochemistry research. A number of reviews discussing the preparation, characterization, and electrochemical behavior of chemically modified electrodes are available [4]. One of the interesting application areas of modified electrodes are in sensors. Sensors are the devices, which are composed of an active sensing material with a signal transducer. The role of these two important components in sensors is to transmit the signal without any amplification from a selective compound or from a change in a reaction. These devices produce any one of the signals as electrical, thermal or optical output signals which could be converted in to digital signals for further processing. Having this concept on modified electrodes, this review leads to the discussion of the theories of non-enzymatic 
electrocatalysis and some selected chemically modified electrode and their potential performance becoming varies from year to year under the process[45].

\subsubsection{Third Generation Enzymatic Glucose Sensors}

Third generation enzymatic glucose sensors involve direct electron transfer between the enzyme and the electrode, without the need for natural or synthetic mediators. This is an ambitious type of enzymatic glucose sensor, yet in recent years it has become increasingly realistic. Achieving mediator free electron transfer between the electrode and redox enzyme is of great fundamental interest. It would be a more perfect system, as the complications of tailored mediators would be avoided, and selectivity and sensitivity could be very high and unhindered. The biggest difficulty in achieving direct electron transfer between the electrode and enzyme is the thick protein in which the redox active centre is embedded or surrounded $[49,59]$.

\subsection{The Disadvantages of Enzymatic Electrochemical Glucose Sensors}

Over the last decades, a number of studies have been conducted to alleviate the drawbacks of enzymatic glucose sensors. The most common and serious problems are insufficient stability, lower reproducibility and influence of oxygen limitation, which is hardly overcome. Stability issues that surround enzymatic systems in all fields of science also hold back the development and application of enzymatic glucose sensors. As review of Wilson and Turner states GOx quickly loses its activity below $\mathrm{pH} 2$ and above $\mathrm{pH}$, and temperature above $44^{\circ} \mathrm{C}$ can cause serious that forms an embryonic hydrous oxide layer of reactive $\mathrm{OH}$ ads mediating oxidation and inhibiting reduction of kinetically slow electrode reactions $[25,51,49]$.

\subsection{Non-Enzymatic Electrochemical Glucose Sensors}

Non-enzymatic sensors will probably become the fourth generation glucose sensors for analytical applications. Considering the flaws of former-generation glucose sensors, this is an ideal system that was first investigated a century ago by Walther Loeb (Loeb, 1909). As reported, glucose has three aqueous isomers denoted as $\alpha$-glucose $(\alpha-G), \beta$ glucose $(\beta-G)$ and $\gamma$-glucose $(\gamma-G)$, as shown in Figs. $4 \alpha$-glucose and $\beta$-glucose are converted through acid-catalyzed hydrolysis via aldehyde-type to glucose ( $\gamma$-glucose). When at equilibrium in water at room temperature these isomers are present at the ratio of 37:63:0.003 for $\alpha-, \beta$-, and $\gamma$-glucose respectively [23], thus indicating that glucose is most stable in its cyclic form.
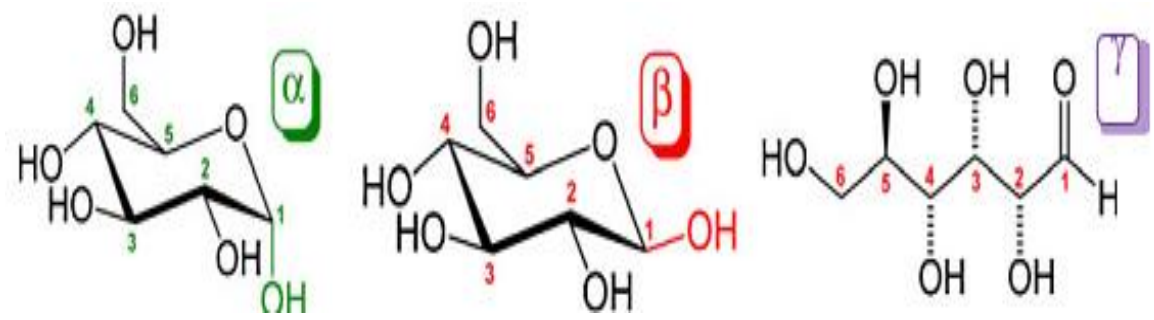

Figure 2 The interconversion of glucose anomers $(\alpha-, \beta-$, and $\gamma-)$ and their relative ratio at $\mathrm{pH} 7$

\subsection{Theories of Non-Enzymatic Electrocatalysis}

Non-enzymatic electrocatalysis come in a number of forms, specifically metals, alloys and bimetallic, carbon-based materials, metal-metal oxide heterogeneous based nanocomposites, layered double hydroxide. Apart from the latter, all the catalysts listed are dependent on a transition metal centre. The process of electro catalysis is generally observed to occur via the adsorption of the analyte to the electrode surface, a process that presumably involves the d-electrons and d-orbitals of the metal substrate that allows it to form a suitable bond with the adsorbate [39].

The proposal of active transition metal centers across the electrode only explains the process of adsorption onto the surface, yet fails to consider the oxidative role of hydroxyl radicals. It has been evident in numerous publications that electro oxidation of glucose and many other organic molecules coincide with the onset of adsorbed OH ads. Burke, 1994 discussed the importance of this hydrous oxide layer on the electrocatalytic process, and proposed the 'Incipient Hydrous Oxide Adatom Mediator' model (IHOAM). This was based on the observation that 'active' surface metal atoms undergo a pre-monolayer oxidation step that forms an incipient hydrous oxide layer of reactive OHads mediating oxidation and inhibiting reduction of kinetically slow electrode reactions. Considering this effect, both the activated chemisorptions model [39] and the IHOAM model [6] will be considered in the following sections regarding each main metal electrode individually. 


\subsubsection{Platinum-Based Electrodes}

As a foremost material, platinum modified electrodes were widely studied in the past decade (see Table 1). It was concluded by early investigators that the product of electrochemical oxidation of glucose on platinum electrodes is similar even in acid, neutral or alkali buffer.

Table 1 List of platinum-based non-enzymatic glucose sensors

\begin{tabular}{|c|c|c|c|c|c|}
\hline Electrode composition & $\begin{array}{l}\text { Sensitivity }(\mu \\
\left.\operatorname{AmM}^{-1} \mathbf{c m}^{-2}\right)\end{array}$ & $\begin{array}{l}\text { Linear range } \\
(\mathrm{mM})\end{array}$ & LOD $(\mu \mathrm{M})$ & $\begin{array}{l}\text { Working } \\
\text { potential }\end{array}$ & Year \\
\hline Pt-disk electrode & 25.2 & Not given & Not given & $+0.35 \mathrm{~V}$ & 2011 \\
\hline Nanoporous pt electrode & 1.65 & $1-10$ & Not given & $+0.40 \mathrm{~V}$ & 2007 \\
\hline Pt nanotubule array electrode & 0.1 & $2-14$ & 1.0 & $+0.40 \mathrm{~V}$ & 2005 \\
\hline Pt nano flowers electrode & 1.87 & $1-16$ & 48 & $+0.03 \mathrm{~V}$ & 2012 \\
\hline Pt nanoporous & 0.64 & $0.1-1.5$ & Not given & +0.40 & 2008 \\
\hline Pt inverse opal & 0.0313 & $0.05-30$ & 0.1 & $+0.05 \mathrm{~V}$ & 2008 \\
\hline Pt nanoparticles & 0.1377 & $0.2-3.2$ & 5.0 & $+0.60 \mathrm{~V}$ & 2007 \\
\hline Dendritic platinum nanostructures & 0.00121 & $1.0-20$ & 1.2 & $+0.50 \mathrm{~V}$ & 2008 \\
\hline
\end{tabular}

Heitbaum reported the mechanism of electrochemical oxidation on platinum electrodes. There are three potential ranges which are shown in Fig. 3 Peak 1 is found in the potential range ( $>0.3$ V versus reversible hydrogen electrode) of the electro adsorption of hydrogen atoms named "hydrogen region. Glucose oxidation in the hydrogen region is associated with the adsorbed hydrogen atoms. The reactive center for the reaction is the hemiacetal group of glucose. Adsorbed glucose and/or products dominate the reaction. The potential of peak 2 is closely located in the region $(<0.3$ to $<0.6 \mathrm{~V}$ versus reversible hydrogen electrode) where the Pt $(\mathrm{OH})$ ad species named "double layer region" form. Peak 3 is recorded in the potential range $(>0.7 \mathrm{~V}$ versus reversible hydrogen electrode) where the platinum surface is practically completely covered with a monolayer of oxygen-containing species, probably PtOad named "oxygen region" [42].

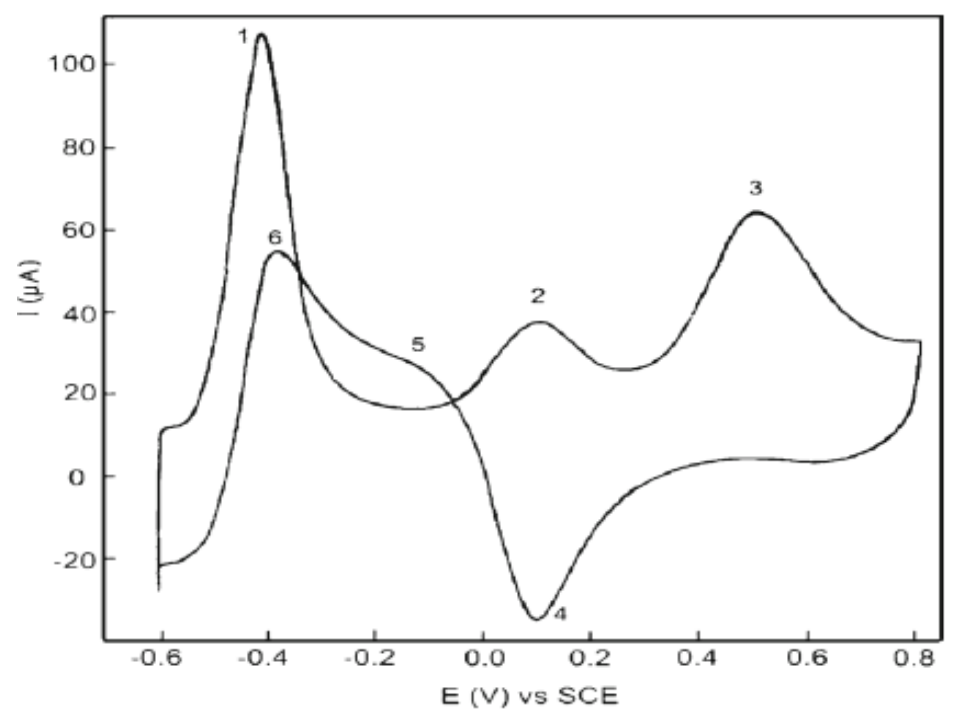

Figure 3 Cyclic voltammogram in the absence (dotted line) and presence (solid line) of 0.1 M glucose in phosphate buffer at pH 7.5 displaying three potential regions where glucose is electrochemically oxidized at a platinum electrode.

\subsubsection{Gold-Based Electrodes}

In general, gold is recognized as a poor substrate for the adsorption or the electro adsorption of species participating in the electro-oxidation of organic substances such as glucose, due to filled d orbitals (Burke, 2004; Hsiao et al., 1992). 
Therefore gold electrodes should display higher electroactivity towards glucose oxidation than platinum electrodes. Although there are numerous investigations (see Table 2), the mechanism of glucose oxidation at gold electrodes has still not been entirely explored [31].

Table 2 List of gold-based non-enzymatic glucose sensors [31]

\begin{tabular}{|l|l|l|l|l|l|}
\hline Electrode composition & $\begin{array}{l}\text { SensitivityC } \\
\boldsymbol{\mu A m M} \mathbf{A m}^{-1} \\
\mathbf{c m}^{-2} \mathbf{)}\end{array}$ & $\begin{array}{l}\text { Linear } \\
\text { range } \\
(\mathbf{m M})\end{array}$ & $\begin{array}{l}\text { LOD } \\
(\boldsymbol{\mu M})\end{array}$ & $\begin{array}{l}\text { Working } \\
\text { potential }\end{array}$ & Year \\
\hline Au Nanocoral & 22.6 & $\begin{array}{l}5.00 \times 10^{-2}- \\
3.00 \times 10^{1}\end{array}$ & $1 \times 101$ & $-0.10 \mathrm{~V}$ & 2010 \\
\hline Urchin like Au sub microstructures & 16.8 & $0.2-13.2$ & 10 & $+0.32 \mathrm{~V}$ & 2010 \\
\hline Porous Au & 11.8 & $2-10$ & 5 & $+0.31 \mathrm{~V}$ & 2007 \\
\hline nanoporous Au film & 66.0 & $1 \times 10^{-5}-11$ & 8.7 & $+0.20 \mathrm{~V}$ & 2011 \\
\hline porous Au electrode & 16 & $0-10$ & 6 & $+0.25 \mathrm{~V}$ & 2007 \\
\hline Au nano/Ti & 0.14 & $1.0-5$ & 0.0148 & $-0.75 \mathrm{~V}$ & 2011 \\
\hline Au nanowire array & 0.04 & $0.1-20$ & 0.003 & $-0.40 \mathrm{~V}$ & 2006 \\
\hline Au nps on NH2-HSMa & $0.0025^{*}$ & $0.2-70$ & 0.10 & $+0.16 \mathrm{~V}$ & 2009 \\
\hline Au-chitosan nps & not given & $0.4-10.7$ & 0.37 & $-0.40 \mathrm{~V}$ & 2009 \\
\hline Au nps DHP film & not given & $0.09-9.9$ & 0.01 & $+0.20 \mathrm{~V}$ & 2007 \\
\hline
\end{tabular}

A possible mechanism was concluded from Arvia's group [30]: (1) the electro-oxidation of glucose on gold electrodes depends on the electrolyte composition, as well as on the $\mathrm{pH}$ and buffer capacity of the solution and the structural characteristics of the electrode; (2) processes occurring in the double-layer potential region are the electro oxidation of bulk glucose, the formation of adsorbed intermediates and the electro oxidation of weakly bound residues; (3) Within the potential range of gold oxide layer electroformation, the electro-oxidation of bulk glucose, the electro-oxidation of strongly bound residues and a corrosion-type reaction comprising the oxidation of glucose and the electro reduction of gold oxide take place.

Due to their high electro activity towards glucose, many gold nanomaterials electrode were fabricated, especially porous gold electrodes. Porous Au films with regular structures have been reported by Xia and co-workers 61 using the hydrogen dynamic template approach which showed excellent electrocatalytic activity and selectivity toward the oxidation of glucose due to the large effective surface area, interconnected macro pores and nanoparticles. Li's group (Xia et al., 2011) report a nanoporous gold film (NPGF) electrode with large roughness factor over 200 by using a rapid one-step anodic potential step method. This electrode showed high electro catalytic activity toward the direct oxidation of glucose with high sensitivity, a wide linear range and good stability in solutions containing high concentrations of chloride ions due to the great roughness. Recently, new structure gold nanomaterials modified electrodes were also studied, such as urchin-like gold sub microstructures, which were synthesized by a seed-mediated method without any template or surfactant agent [53].

Electrochemical characterization indicated that these urchin-like gold sub microstructures have better catalytic activity for glucose oxidation compared with flower-like gold sub microstructures, which could be ascribed to their higher surface to volume ratio. This sensor displays a wide linear range from 0.2 to $13.2 \mathrm{mM}$ with a high sensitivity of 16.8 $\mu \mathrm{AmM}^{-1} \mathrm{~cm}^{-2}$, and a detection limit of $10 \mu \mathrm{M}$. Another group developed a simple electrochemical deposition method to grow different gold nanostructures on commercial carbon electrodes. Among the electrodes fabricated the nanocoral, which exposed planes, shows the greatest sensitivity toward a kinetic controlled glucose oxidation due to the highest real surface area. Such a gold nanocoral modified electrode offered the greatest sensitivity, $22.6 \mu \mathrm{A} \mathrm{mM}-1 \mathrm{~cm}^{-2}$, an extended linear range, $5.00 \times 10^{-2} \mathrm{mM}$ to $3.00 \times 101 \mathrm{mM}$, and a low detection limit, $1.00 \times 101 \mu \mathrm{M}$ [9].

In addition, glucose oxidation by the nanocoral electrode started at $-0.280 \mathrm{~V}$, more negatively than the commercial Au electrode as the working electrode, due to the presence of exposed Au surfaces on the electrode. The feature was applied to oxidize glucose selectively in the presence of ascorbic acid and uric acid, common interferences found in physiological analytes. With an applied voltage at $-0.100 \mathrm{~V}$, the AA oxidation (starting at $-0.080 \mathrm{~V}$ ) can be avoided, while the glucose 
oxidation still provides a significant response. Indeed, gold-based electrodes are more selective than platinum electrodes, but they still exhibit an affinity for the adsorption of chloride ions in neutral conditions. At the same time, the cost effectiveness of using gold materials in the fabrication of disposable electrodes must be considered.

\subsubsection{Nickel-Based Electrodes}

Recently nickel-based electrodes have been extensively explored as catalysts for organic compound oxidation in an alkaline medium (see Table 3).

Table 3 List of nickel-based non-enzymatic glucose sensors [40].

\begin{tabular}{|c|c|c|c|c|c|}
\hline Electrode composition & $\begin{array}{l}\text { Sensitivity } \\
\left(\mu \mathrm{A} \quad \mathbf{m M}^{-1}\right. \\
\left.\mathbf{c m}^{-2}\right)\end{array}$ & $\begin{array}{l}\text { Linear range } \\
(\mathrm{mM})\end{array}$ & LOD $(\mu \mathrm{M})$ & $\begin{array}{l}\text { Working } \\
\text { potential }\end{array}$ & Year \\
\hline $\begin{array}{l}\mathrm{Ni} \text { nanowire arrays } \\
\text { modified GCE }\end{array}$ & 1043 & $5 \times 10^{-4}-7$ & 0.1 & $+0.55 \mathrm{~V}$ & 2009 \\
\hline Nickel electrode & not given & $0.10-2.50$ & 40 & $+0.55 \mathrm{~V}$ & 2007 \\
\hline Ni powder & $4.00 \times 10^{-5}$ & $5 \times 10^{-4}-5.0$ & 0.1 & $+0.45 \mathrm{~V}$ & 2005 \\
\hline Ni implanted BDD & $2.8 \times 10^{-3}$ & $0.001-0.05$ & 0.67 & $+0.70 \mathrm{~V}$ & 2004 \\
\hline $\mathrm{Ni}-\mathrm{NDC}$ & not given & $5 \times 10^{-5}-0.5$ & 0.02 & $+0.40 \mathrm{~V}$ & 2003 \\
\hline Ni BPE. & not given & 3 orders of mag & 0.48 & $+0.55 \mathrm{~V}$ & 2008 \\
\hline Ni wire & not given & not given & $5.90 \times 10^{-7}$ & $+0.50 \mathrm{~V}$ & 1990 \\
\hline Nickel modified GCE & not given & not given & $1.77 \times 10^{-4}$ & $+0.40 \mathrm{~V}$ & 1991 \\
\hline $\mathrm{Ni}-\mathrm{MCH}$ & not given & not given & $2.50 \times 10^{-5}$ & $+0.45 \mathrm{~V}$ & 1994 \\
\hline$\left(\mathrm{Ni}{ }^{I I} \mathrm{~L}\right) \mathrm{n}-\mathrm{CME}$ & $8.60 \times 10^{-3}$ & $0.005-0.5$ & $5.90 \times 10^{-6}$ & $+0.50 \mathrm{~V}$ & 1994 \\
\hline $\mathrm{Ni}-\mathrm{CME}$ & not given & $0.0025-0.1$ & $2.50 \times 10^{-6}$ & $+0.51 \mathrm{~V}$ & 1995 \\
\hline
\end{tabular}

Previously, Sattar and Conway [41] reported the surface oxidation of nickel anodes in alkaline solution in detail. According to the result, Fleishmann [11] and co-workers firstly studied and established the mechanism of the behavior of a nickel anode on the electrooxidation of numerous organic materials, including glucose.

It is accepted by many other works that the catalytic component is a Ni (III) oxyhydroxide species, the oxidized partner to the $\mathrm{Ni}(\mathrm{OH})_{2} / \mathrm{NiOOH}$ redox couple. Zhao' group [59] has concluded that the oxidation of glucose to glucolactone (two hydrogens are liberated in this process) was catalyzed by the Ni (III)/ (II) redox couple according to the following reactions:

$$
\begin{aligned}
& \mathrm{Ni}(\mathrm{OH})_{2}+\mathrm{OH}-------\mathrm{NiOOH}+\mathrm{H}_{2} \mathrm{O}+\mathrm{e}- \\
& \mathrm{NiOOH}+\text { glucose ------ } \mathrm{Ni}(\mathrm{OH})_{2}+\text { glucolactone }
\end{aligned}
$$

Compared with platinum-based and gold-based electrodes, nickel-based electrodes seem to be the most sensitive of the non-enzymatic electrode materials. But there are also some drawbacks when applied to electro catalyzing glucose. The greatest problem is that they cannot be used in solutions with $\mathrm{pH}$ equal to or less than 7 because the catalysis is highly dependent on the presence of $\mathrm{OH}^{-}$anions.

\subsubsection{Copper-Based Electrodes}

In the pursuit of more economical electro catalysts for non-enzymatic glucose sensors without the compromise of sensitivity and specificity, considerable attention has been focused on copper-based materials (see Table 4) such as metallic $\mathrm{Cu}$ [55], cupric oxide ( $\mathrm{CuO})$ [20], cuprous oxide $\left(\mathrm{Cu}_{2} \mathrm{O}\right)$ [22, 24], CuxO and copper (I) sulfide ( $\left.\mathrm{Cu}_{2} \mathrm{~S}\right)$ due to their outstanding catalytic ability and ready availability. 
In the present research, Hou's group [58] prepared uniformly distributed 1-D Cu NWs with an average diameter of 150 $\mathrm{nm}$ and an average length of $30 \mathrm{~mm}$ by a facile, scalable, wet-chemistry route. Under the optimized conditions, the developed glucose sensor can detect glucose with an excellent LOD, a wide linear range, and high sensitivity, which can be attributed to the good catalytic ability, large surface area, excellent conductivity, and efficient electron transfer of the $\mathrm{Cu}$ NWs. More importantly, the proposed non-enzymatic glucose sensor was successfully applied to the determination of glucose in human serum samples with good accuracy and high precision.

Table 4 List of copper-based non-enzymatic glucose sensors [58]

\begin{tabular}{|c|c|c|c|c|c|}
\hline Electrode composition & $\begin{array}{l}\text { Sensitivity }(\mu \\
\text { A mM-1 } \\
\text { cm-2) }\end{array}$ & $\begin{array}{l}\text { Linear range } \\
(\mathrm{mM})\end{array}$ & $\begin{array}{l}\text { LOD } \\
(\mu \mathrm{M})\end{array}$ & $\begin{array}{l}\text { Working } \\
\text { potential }\end{array}$ & $\begin{array}{l}\text { Year of } \\
\text { investig } \\
\text { ation }\end{array}$ \\
\hline $\begin{array}{l}\text { Cu microden drites modified } \\
\text { GCE }\end{array}$ & not given & $1.4 \times 10^{-3}-3.8$ & 1.4 & $+0.40 \mathrm{~V}$ & 2012 \\
\hline Cu Polyhedron modified GCE & 2.1064 & $0.2-4.2$ & 70 & $+0.50 \mathrm{~V}$ & 2011 \\
\hline $\begin{array}{l}\text { pillar-like-structure } \mathrm{Cu} \text { film } \\
\text { modified ITO }\end{array}$ & 699.4499 & $\begin{array}{l}1 \times 10^{-3}- \\
5 \times 10^{-1}\end{array}$ & 0.5 & $+0.40 \mathrm{~V}$ & 2011 \\
\hline $\mathrm{CuO} / \mathrm{Cu}$ electrode & 761.9 & $2 \times 10^{-3}-20$ & 1 & $+0.70 \mathrm{~V}$ & 2009 \\
\hline $\mathrm{Cu}$ nanobelts & 0.0798 & $0.01-1.13$ & 10.0 & $+0.40 \mathrm{~V}$ & 2010 \\
\hline Cu implanted BDD & not given & $1.0-5.0$ & not given & $+0.60 \mathrm{~V}$ & 2006 \\
\hline Cu/SAMs 2006 & not given & $3 \times 10-3-10$ & 0.7 & $+0.70 \mathrm{~V}$ & 2006 \\
\hline Cu nanoporous & 220 & $0.01-0.5$ & 40.0 & $+0.45 \mathrm{~V}$ & 2009 \\
\hline $\mathrm{Cu}$ wire & 37.9 & $0.01-1.0$ & $5.0 \times 10-6$ & $+0.50 \mathrm{~V}$ & 2009 \\
\hline $\mathrm{Cu}$-BDD electrode & 2.30 & $0.001-0.05$ & 10.0 & +0.65 & 2004 \\
\hline $\begin{array}{l}\text { electrochemically-oxidized } \mathrm{Cu} \\
\text { electrode }\end{array}$ & not given & $\begin{array}{l}\times 10-10- \\
1 \times 10-6\end{array}$ & $22.00 \times 10-7$ & $+0.45 \mathrm{~V}$ & 1996 \\
\hline Cu modified GCE & not given & not given & $5.90 \times 10^{-5}$ & $+0.40 \mathrm{~V}$ & 1994 \\
\hline Nafion/Cu-f/GCE & $\begin{array}{ll}65.56 & \mu \mathrm{A} \\
\mathrm{mM}-1 & \end{array}$ & $\begin{array}{l}2 \times 10^{-6}- \\
75 \times 10^{-6}\end{array}$ & $1 \times 10^{-6}$ & $+0.70 \mathrm{~V}$ & 2012 \\
\hline
\end{tabular}

\subsubsection{Metal-metal Oxide Heterogeneous Based Electrodes}

Considering the same high electro conductivity as carbon materials such as carbon nanotubes and graphene, many metal heterogeneous based electrodes were widely studied. In contrast to noble metal based electrodes, metal based electrodes show an excellent electrocatalytic activity for glucose oxidation without observable self-poisoning. Especially the copper-based modified electrodes exhibit outstanding catalytic activity towards glucose. Hence, it is pertinent to explore and develop a sensor with high selectivity and stability, fast response time and portability of use for the determination of glucose based on metal based modified electrodes (see Table 5) [40].

As a very famous electric material, copper was largely considered for use as the substrate to fabricate metal-based modified electrodes to achieve enzyme-free glucose detection. Zhang's group [31] reported CuO nanoplatelets grown on $\mathrm{Cu}$ foils, and the electrode exhibits a sensitivity of $3490.7 \mu \mathrm{A} \mathrm{mM}^{-1} \mathrm{~cm}^{-2}$ to glucose, which is much higher than that of most reported enzyme-free glucose sensors. The linear range was obtained over a concentration of up to0.80 mM with a detection limit of $0.50 \mu \mathrm{M}$ (signal/noise03) in alkaline media. 
Table 5 List of metal-metal oxide heterogeneous based non-enzymatic glucose sensors [40].

\begin{tabular}{|c|c|c|c|c|c|}
\hline Electrode composition & $\begin{array}{l}\text { Sensitivity } \\
\left(\mu \mathrm{A} \quad \mathbf{m M}^{-1}\right. \\
\left.\mathbf{c m}^{-2}\right)\end{array}$ & $\begin{array}{l}\text { Linear range } \\
(\mathrm{mM})\end{array}$ & $\begin{array}{l}\text { LOD } \\
(\mu \mathrm{M})\end{array}$ & $\begin{array}{l}\text { Working } \\
\text { potential }\end{array}$ & Year \\
\hline $\mathrm{Au}-\mathrm{Pt}$ hybrid electrode & 39.53 & $1-20$ & 25 & $+0.40 \mathrm{~V}$ & 2011 \\
\hline CuNidendritic material electrode & not given & not given & 48 & $+0.65 \mathrm{~V}$ & 2007 \\
\hline $\begin{array}{l}\text { Pinecone-shapedPtPb } \\
\text { nanostructures electrode }\end{array}$ & 10.71 & $8.4 \times 10^{-3}-12$ & 8.4 & $-0.10 \mathrm{~V}$ & 2011 \\
\hline NiO-MFs modified electrode & 1785.41 & $1 \times 10^{-3}-0.27$ & $3.3 \times 10^{-2}$ & $+0.50 \mathrm{~V}$ & 2011 \\
\hline GC/npAu-Ru/CHIT electrode & 240 & $0-6$ & 1.7 & $+0.10 \mathrm{~V}$ & 2011 \\
\hline $\begin{array}{l}\text { Palladium-modified epoxy-silver } \\
\text { electrode }\end{array}$ & not given & $1-20$ & not given & $+0.35 \mathrm{~V}$ & 2011 \\
\hline $\mathrm{Au}$ at Pd-ILs-Au at Pd/GCE & not given & $5 \times 10-6-5 \times 10-2$ & $1 \times 10-3$ & $0.00 \mathrm{~V}$ & 2010 \\
\hline OPPy modified Pd/Si MCP electrode & 370 & $2.06 \times 10-3-24$ & 2.06 & $+0.08 \mathrm{~V}$ & 20011 \\
\hline Pd-coated electrode & not given & $\begin{array}{l}2.86 \times 10-3- \\
1.07 \times 10-1\end{array}$ & 0.78 & $-0.10 \mathrm{~V}$ & 2010 \\
\hline $\mathrm{Pd}-\mathrm{Ni} / \mathrm{Si}$ nanowire electrode & 190.72 & not given & 2.88 & $-0.06 \mathrm{~V}$ & 2011 \\
\hline Pt-Ir nanoporous & $0.0937 \mathrm{~V}$ & $1.0-10$ & not given & +0.10 & 2011 \\
\hline $\mathrm{Pt} / \mathrm{Ni}$ Nanowire array electrode & 920 & $2 \times 10-3-2$ & 1.5 & $+0.45 \mathrm{~V}$ & 2008 \\
\hline $\mathrm{PtPb}$ nanoporous & 0.0108 & $1.0-16$ & not given & $-0.08 \mathrm{~V}$ & 2008 \\
\hline
\end{tabular}

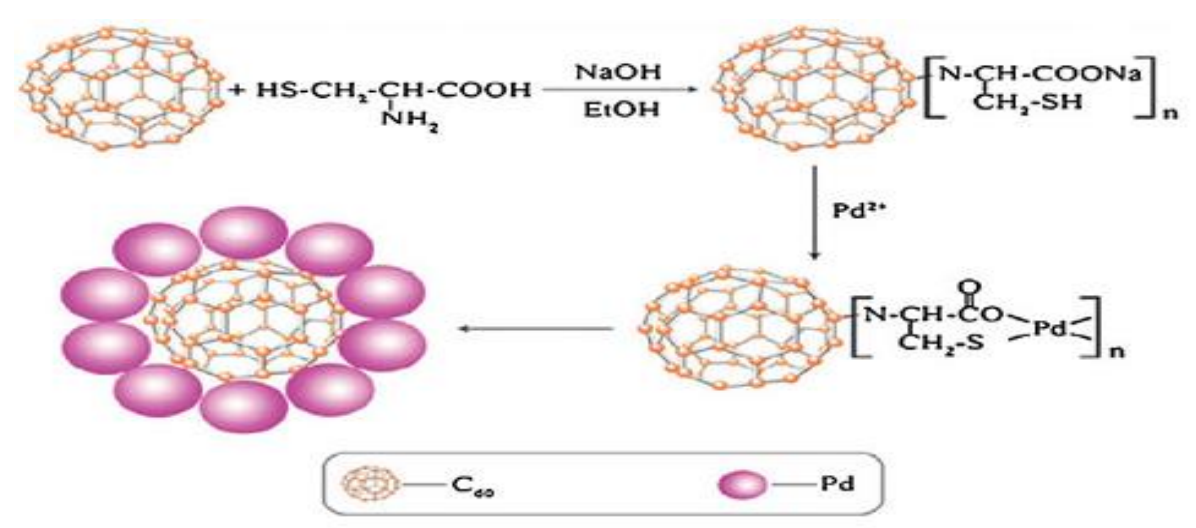

Figure 4 Typical synthetic process of $\mathrm{Pd}$ at $\mathrm{C}_{60}$-nanoparticles.

An enzyme less biosensor based on $\mathrm{CuxO} / \mathrm{Cu}$ electrodes with $\mathrm{CuxO}$ nanostructure material being composed of $\mathrm{Cu}_{2} \mathrm{O}$ and $\mathrm{CuO}$ was investigated [24]. The biosensor based on $\mathrm{CuxO} / \mathrm{Cu}$ exhibited excellent performance for glucose detection, giving a linear dependence between current and glucose concentration (R00.996), with a low detection limit (0.049 $\mathrm{mM})$ and high sensitivity $\left(1.62 \mathrm{~mA} \mathrm{~cm}^{-2} \mathrm{mM}^{-1}\right)$. The CuxO/Cu sensor was applied and checked in the glucose determination in blood serum samples. 


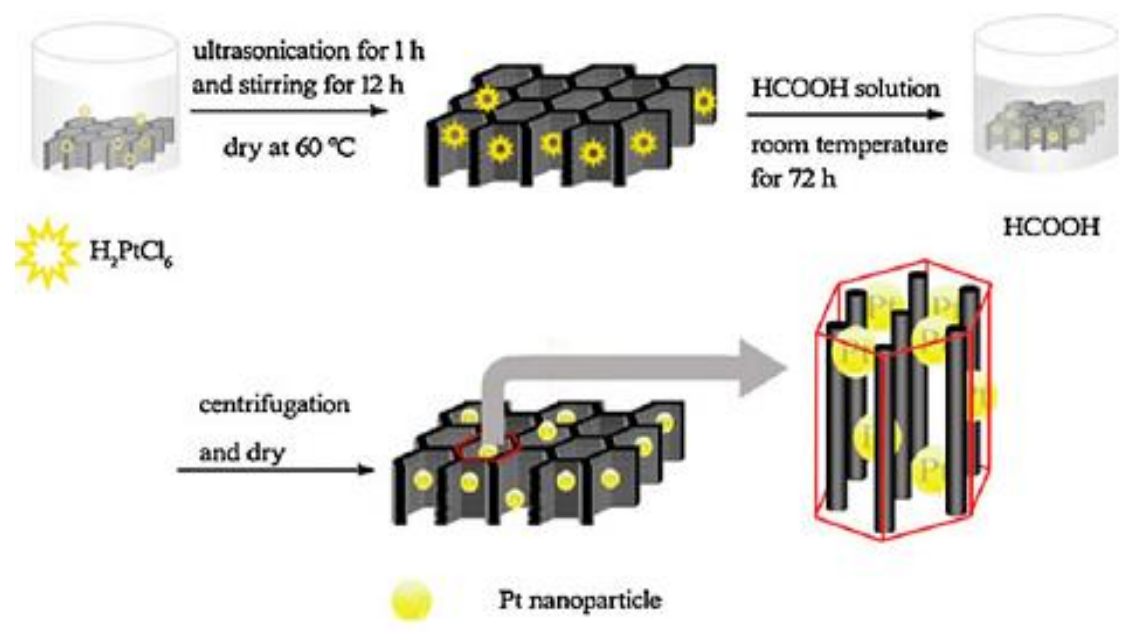

Figure 5 Illustration of the preparation of Pt/OMCsnanocomposite.

Zhang's group also studied $\mathrm{Ag}_{2} \mathrm{O}$ Nano-walls on $\mathrm{Cu}$ substrate modified electrodes on a non-enzymatic glucose sensor. At an applied potential of $0.4 \mathrm{~V}$, the sensor exhibited an ultra-high sensitivity to glucose (GO) of $298.2 \mu \mathrm{A} \mathrm{mM}^{-1}$. A linear response was obtained over a concentration range of $0.2 \mathrm{mM}$ to $3.2 \mathrm{mM}$ with a detection limit of $0.01 \mathrm{mM}$ (S/N03). Satisfyingly, the $\mathrm{Cu}-\mathrm{Ag}_{2} \mathrm{O}$ nanowall modified electrode was also successfully employed to eliminate interferences from uric acid, ascorbic acid and also fructose (FO) during the catalytic oxidation of glucose. Although there are too many copper-based electrodes, other metal-based electrodes have also been reported, e.g. gold, titanium [58] etc.

\subsubsection{Carbon-Based Electrodes}

The carbon community, including 0-dimensional carbon materials such as fullerenes, nano diamond, conducting carbon black nanoparticles, 1-dimensional carbon nanotubes, and 3-dimensional carbon materials such as diamond and graphite [44], has attracted tremendous attention from both the experimental and theoretical scientific communities during the past 20 years. Recently, 2-dimensional graphene was also discovered by Novoselov and Geim [35] and widely studied immediately.

\subsubsection{Alloys and Bimetallic Based Electrodes}

Recently, alloys and bimetallic based electrodes were widely used as non-enzymatic glucose sensors due to their highly desirable electronic and catalytic properties. It should be pointed out that Vasil'ev [2] firstly commented on the improved electro-oxidation of organic compounds at alloyed platinum electrodes, stating they exhibited the highest catalytic activity toward small organic molecules.

Undoubtedly alloys and bimetallic could form a synergistic electronic response, in which the catalytic benefits of each component combine to form a 'super' catalyst $[56,19]$. Hence, alloys and bimetallic based electrodes were fabricated to decrease some drawbacks such as poison, sensitivity and selectivity.

\section{7 $\mathrm{CuO/ZnO} \mathrm{Nanostructures} \mathrm{for} \mathrm{Sensor} \mathrm{Application}$}

Recently, hybrid nanostructured materials with a high surface area, good conductivity and permeability have been considered to be one of the most significant functional materials for the various emerging research fields, such as, sensor, energy conversion and environmental remediation. But, the performance of these hybrid nanostructured materials mainly depends on their size, morphology, composition, structure, crystal phases and crystal face. Therefore, the controlled synthesis of hybrid metal oxide nanostructures is of considerable interest to achieve the required size, morphology and structure of the hybrid nanostructure. To the best of our knowledge, there are very few reports on the $\mathrm{CuO} / \mathrm{ZnO}$ nanocomposites for the non-enzymatic glucose sensing applications [17].

\subsection{Techniques and Instrumentation in Electrochemical Analysis}

Traditional techniques are the most commonly used techniques for the determination of different compounds in various field of real sample analysis. This techniques are mainly based on chromatographic technique including gas chromatography(GC) and high performance liquid chromatography (HPLC) [3,36,47], spectrophotometry [5], fluorescence spectrum and UV [50] or electrochemical detection [35,46]; at that moment, they were reported as accurate, sensitive and selective techniques. 
Even though they are accurate and selective, most of these conventional analytical methods employ pre- or post-column derivatazation procedures to confer volatility, fluorescence or UV absorption properties to the analytes, thus increasing the time of analysis, cost and analytical uncertainty to the assay. The analytical methods employed for their analysis, as well as the sample pretreatment methods have been comprehensively reviewed by $[52,18,8]$. Normally, HPLC has been used in combination with fluorescence and UV-Vis detection after derivatazation in order to decrease the sample analysis time and cost than gas chromatography and liquid chromatography but with limited sensitivity. These conventional analytical methods (e.g. chromatographic methods) often constitute an important impediment or their application on regular basis [43].

\subsection{Selected Modern Electrochemical Technique}

\subsubsection{Stripping Voltammetry Techniques}

There are several techniques of stripping. But, here, we will discuss only the three of stripping analysis, namely anodic striping voltammetry, cathodic striping voltammetry and adsorptive striping voltammetry.

\section{Anodic Stripping Voltammetry (ASV)}

Anodic stripping voltammetry is most widely used form of stripping analysis. It is used for the trace analysis of the analyte (metal ions or organic compound) and it's consisting of two steps. A) Pre concentration; where the analyte is pre concentrated by electro deposition into the small-volume working electrode. For example if our electrode is mercury electrode, the following reaction will occur on the surface of mercury electrode.

$\mathrm{M}^{\mathrm{n}^{+}}+\mathrm{n}^{\mathrm{e}^{-}}+\mathrm{Hg} \rightarrow \mathrm{M}(\mathrm{Hg})$

As shown from this equation the analyte is reduced at the mercury electrode forming amalgam at negative (cathodic) potential. b) Reoxidizing and stripped out of the electrode; the amalgamated analyte is by applying a positive (anodic) potential. As a result of this reaction, peak current will be produced and recorded. This reaction can be represented in the following.

$$
\mathrm{M}(\mathrm{Hg}) \rightarrow \mathrm{M}^{\mathrm{n}^{+}}+\mathrm{n}^{\mathrm{e}^{-}}+\mathrm{Hg}
$$

The resulting voltammogram provides us information from the analyte of the interest and this result canbe interpreted in terms of peak current and peak potential $(E)$. That is, peak current $(I p)$ is proportional concentration of the analyte present in the sample of reproducible deposition conditions is unspecified and the peak potential is used to identify the analyte in the sample [13].

\section{Cathodic Stripping Analysis (CSV)}

Cathodic stripping voltammetry is used to determine many of organic and inorganic compounds that forms insoluble salts with electrode material. It consider as mirror image of ASV. Because of it involves positive deposition of the analyte when anodic potential is applied to the working electrode followed by stripping in a negative-going potential scan.

$A^{n^{-}}+H g \leftrightarrows H g A^{+}+n e^{-}$

Where the forward arrow indicates deposition of the analyte and the back ward arrow indicates stripping of the analyte. The sensitivity of CSV depends on the amount the analyte that can be placed in a given period of time, the density of the formed insoluble salt film and the dissociation rate of the insoluble mercury compound during the stripping step [1].

\section{Adsorptive Stripping Voltammetry (AdSV)}

Adsorptive stripping voltammetry is quite similar to ASV and CSV methods. The primary difference could be explained as using adsorption in pre concentration step. Adsorptive stripping voltammetry can be employed in the trace analysis of a wide variety of organic and inorganic analyte. In case of metal ions, it could be easily determined by AdSV when it reacts with suitable ligand to form a complex which is adsorbed on the electrode surface. Also, metal ions will be determined by AdSV when it reacts with ligand adsorbed on the electrode surface. Organic compounds may be determined by AdSV. The adsorption process play important role in the accumulation process. When the organic compound contains electrochemically reducible or oxidizable function groups, it reacts with oxidized electrode material and the formed compound is adsorbed [21, 29]. 


\section{Potentiometric Stripping Analysis (PSA)}

In Potentiometric stripping analysis, stirring play important role to facilitate the transport of oxidant. This can be indicated in the following reaction equation. $\mathrm{M}(\mathrm{Hg})+$ oxidant $\rightarrow \mathrm{Mn}$. Oxidation will be occurs when constant anodic current passed through the working electrode. As the oxidation proceeds, the variation of the working electrode potential is recorded and the stripping curve is obtained. The transition time $\left(t_{M}\right)$ consumed during the oxidation process is quantitative measure of the concentration of the analyte: $t_{M} \alpha C_{M}{ }^{{ }^{+}} t_{d} / C_{o x}$ This means, when the concentrations of oxidant (Cox) decrease the signal obtained from the analyte will be increase [12, 57].

\subsubsection{Cyclic Voltammetry (CV)}

Cyclic voltammetry (CV) has becomes an important and widely used in many areas of electrochemistry. It is rarely used for the quantitative determination of the sample under analysis, but it is widely used for study of redox reactions and get much information about the chemical reactions occurs in a given real sample. Cyclic voltammetry is a rapid voltage scan technique in which the direction of voltage scan is reversed when the applied potential at working electrode is in both forward and reverse directions, and then the resulting current will be recorded. The scan rate in the forward and reverse direction is normally the same. $\mathrm{CV}$ can be also used in single cycle or multicycle modes. The measurable parameters in cyclic voltammetry are anodic and cathodic peak potential $\left(E_{p a}\right.$ and $\left.E_{p c}\right)$, anodic and cathodic peak current $\left(i_{p a}\right.$ and $\left.i_{p c}\right)$ and the half peak potentials $\left(E_{P} / 2\right)$ at which the cathodic and anodic currents reach half of their peak value.

Finally, the peak current density in CV is given by Randles-Sevcik equation: $i_{p}=\left(2.69 \times 10^{5}\right) n^{3 / 2} A D^{1 / 2} V^{1 / 2} C$. Where $n$ is the number of electrons in redox reaction, $\mathrm{A}$ is the area of the working electrode, $\mathrm{D}$ is the diffusion coefficient for electro active species, $\mathrm{v}$ is scan rate and $\mathrm{C}$ is the concentration of electro active species at the electrode. For well-behaved system the anodic and cathodic peak current density are equal and the ratio $\left(i_{p a} / i_{p c}\right)$ is one. The half wave potential $E_{1 / 2}$ is the midway between the anodic and cathodic peak potential and is given as $E_{1 / 2}=E_{p, a}+E_{p, c} / 2$. Scanning the potential in both directions provides us with the opportunity to explore the electrochemical behavior of species generated at the electrode.

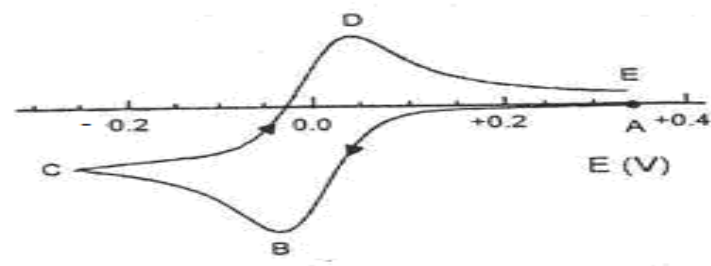

Figure 6 Cyclic voltammogram shows a species which undergoes a reversible reduction potential at $E^{0^{\prime}}=0.00 \mathrm{~V}$, where $\mathrm{A}$ is initial potential, $\mathrm{B}$ is cathodic peak, $\mathrm{C}$ is switch potential, $\mathrm{D}$ the anodic peak and $\mathrm{E}$ final potential

\subsubsection{Pulse Voltammetry}

This is a kind of voltammetry that consists of a series of potential pulses of increasing amplitude. The measurement of peak current produced usually carried out at near the end of each pulse and at certain period, the resulting current equal zero. This may be explained between the pulses where the electrode is kept at a constant potential at which there is no chemical reaction occurs in the cell $[12,14]$.

\section{Differential Pulse Voltammetry (DPV)}

Comparison between normal pulse voltammetry (NPV) and differential pulse voltammetry (DPV) is that in differential pulse voltammetry DPV potential pulse is fixed and superimposed on slowly changing base potential. The current is measured at two points; before the application of the pulse and the end of the pulse. The first current is subtracted from the second and then the current difference $\left\{\Delta i=i\left(t_{2}\right)-i\left(t_{1}\right)\right\}$ is plotted versus the applied potential. The highest of the produced peak current is proportional to the concentration of analyte and expressed as following expression,

$$
i_{p}=\frac{n F A D^{1 / 2} C}{\sqrt{\pi t}_{m}}\left(\frac{1-\alpha}{1+\alpha}\right)
$$




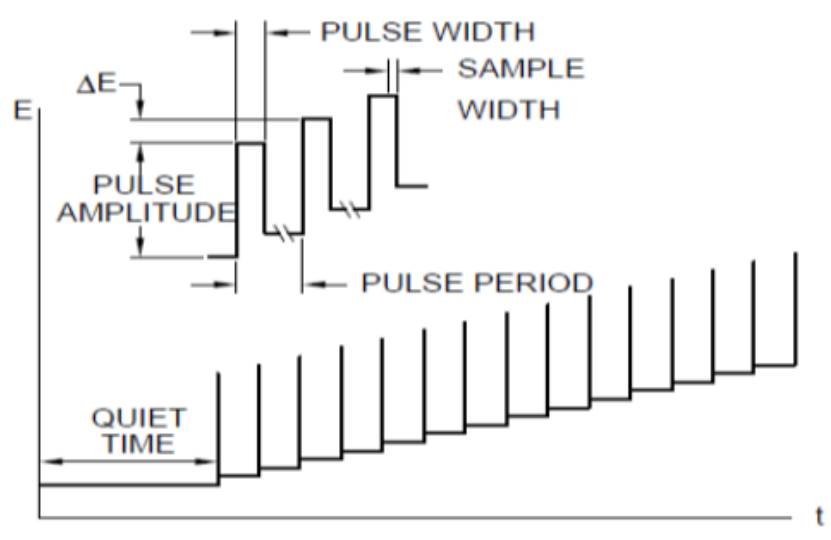

Figure 7 Potential wave form for DPV

\subsubsection{Square Wave Voltammetry (SWV)}

In square wave Voltammetry (SWV) waveform consist of normal square wave which are superimposed on the base of staircase potential, and is applied to the working electrode. The current is doubled during each square wave cycle, once at the end of the forward pulse and the other at the end of the reverse pulse respectively. The difference between the two measurements is plotted versus the base potential. The major advantage of SWV is its speed while it s compared with square wave and differential pulse Voltammetry for reversible and irreversible cases indicated that the squarewave currents are 4 and 3.3 times higher, respectively, than the analogous differential-pulse response [12].

\subsubsection{Potentiometry}

Potentiometry is a type of electrochemical technique provides us information about the composition of the sample through the potential appearing between tow electrodes and this method was recently, developed by suggestion of use ion selective electrode (ISE). This electrode characterized by its selectivity and sensitivity. The equipment used in Potentiometric measurement consists of ion selective electrode (ISE) which reference electrode and potential measuring device. The main idea of ion selective electrode is use membrane-based devices. The composition of such membrane will bind the analyte ions with high sensitivity and selectivity leaving the co-ions behind and such electrodes show rapid response, wide linear range, not affected by color or turbidity, not destructive and very inexpensive [12,7].

\section{Conclusion}

This review summarized the recent literature of almost 5 years regarding electrodes based on various materials and explored its successful application in non-enzymatic glucose sensors. Some of the publications present comprehensive and detailed studies, novel and simple ways to prepare electrode materials, a strong catalytic ability towards analytes, high sensitivity, and successful application of the sensors, hence implying promising development and application potential. The advancement may depend on research into grapheme, metal and layered double hydroxide based materials, presently a very hot topic, though. The technology involving those new materials is certain to rapidly develop in the near future, possibly leading to a useful non-enzymatic glucose sensor. But, just as shown in this review, most of the proposed sensors are first tested and studied in buffers, which simulate similar conditions as in biological matrices. The development of such sensors for clinical applications with biological matrices is far more complex, and there is not always a perfect match between the normal concentrations and the analytical ranges of the sensors developed. That is, the performance of sensors using buffers in simulated conditions in the laboratory cannot be directly transposed to clinical conditions. Once developed on the laboratory scale, there is room for further improvements of non-enzymatic glucose sensors at the clinical level and their application to real biological samples. Although there are many researchers wanting to achieve the application of non-enzymatic glucose sensors, we must recognize that it is still a tremendous challenge. In my option, the enzymatic glucose sensor will be widely used in the long run. In conclusion, the application of nonenzymatic glucose sensors requires the co-efforts of researchers worldwide. We look forward to even more brilliant developments of non-enzymatic glucose sensors. 


\section{Compliance with ethical standards}

\section{Acknowledgments}

The Author thanks to Department of chemistry, MWU, Bale Robe, Ethiopia.

\section{Disclosure of conflict of interest}

The author does not have any financial support to write this review.

\section{References}

[1] Arnold G. Adsorptive stripping voltammetry or cathodic stripping voltammetry? Methods of accumulation and determination in stripping voltammetry. Analytical Proceedings Including Analytical Communications, 1994; 31:313-317.

[2] Bagotskii, V.S. and Vasil'ev, Y.B. Mechanism of electrooxidation of methanol on the platinum electrode. Electrochimica Acta, 1967; 12:1323-1343.

[3] Baig, S.A., Akhtera, N.A., Ashfaq, M. and Asi, M.R. Determination of the organ phosphorus pesticide in vegetables by high-performance liquid chromatography. American-Eurasian Journal of Agricultural and Environmental Science, 2009; 6(5):513- 519.

[4] Bard, A.J. and Faulkner, R. L. 2001. Electrochemical methods, fundamentals and applications. 580-631 in: John Wiley and Sons, Inc, New York.

[5] Bhadekar, R., Pote, S., Tale, V. and Nirichan, B. Developments in analytical methods for detection of pesticides in environmental samples. American Journal of Analytical Chemistry, 2011; 2:1-15.

[6] Burke, L.D. Premonolayer oxidation and its role in electrocatalysis. Electrochimica Acta, 1994; 39:1841-1848.

[7] Burke, L.D. Scope for new applications for gold arising from the electrocatalytic behavior of its metastable surface states. Gold Bull, 2004; 37:125-135.

[8] Chen, D.J., Lu, Y.H., Wang, A.J., Feng J.J., Huo, T.T. and Dong, W.J. Facile synthesis of ultra-long Cu microdendrites for the electrochemical detection of glucose. Journal of Solid State and Electrochemistry, 2012; 16:1313-1321.

[9] Cheng, T.M., Huang, T.K., Lin, H.K., Tung, S.P., Chen, Y.L., Lee, C.Y. and Chiu, H.T. Exposed gold nanocoral electrode as low onset potential selective glucose sensor. American Chemical Society Applied Material and Interfaces, 2010; $2: 2773-2780$.

[10] Chung-Hsiao East Road, Taipei 106, Taiwan (ROC), electrochemical sensors and biosensors composed of nanowires as sensing material. 2008; 8:290-313.

[11] Degani, Y. and Heller, A. Electrical communication between redox centers of glucose oxidase and electrodes via electro statically and covalently bound redox polymers. Journal of American Chemical Society, 1989; 111:23572358.

[12] Farghaly, O.A. Hameed, R.S., Alhakeem, H. and Abu, N. Analytical application using modern electrochemical techniques .International Journal of Electrochemical Science, 2014; 9:3287 - 3318.

[13] Figura, P. and McDuffie, B. Speciation of heavy metal in natural water. Analytical Chemistry, 1979; 51:120.

[14] Fleischmann, M., Korinek, K. and Pletcher, D. The oxidation of organic compounds at a nickel anode in alkaline solution. Journal of electro analytical chemistry and Interfacial electrochemistry, 1971;31:39-49.

[15] Guinovart, T., Parrilla, M., Crespo, G.A., Rius, F.X. and Andrade, F.J. Potentiometric sensors using cotton yarns, carbon nanotubes and polymeric membranes. Analyst, 2013; 138:5208-5215.

[16] Guo, M., Hong S., Tang, X., Fang, D., and Xu, X. Ultrasonic electrodeposition of platinum nanoflowers and their application in nonenzymatic glucose sensors. Electrochimica Acta, 2012; 63:1-8.

[17] Heller,A. and Feldman, B. Electrochemistry in diabetes management. Account of Chemistry Research, 2010; 43:963-973.

[18] Hsiao, M., Adzic, R. and Yeager, B. The effects of adsorbed anions on the oxidation of d-glucose on gold single crystal electrodes. Electrochimica Acta, 1992; 37:357-363. 
[19] Jafarian, M., Forouzandeh, F., Danaee, I, Gobal,F., and Mahjani, M. Electrocatalytic oxidation of glucose nikel and nikel copper alloy modified glassy carbon electrode. Journal of Solid State of Electrochemistry, 2009; 13:11711179.

[20] Jiang, L. and Zhang, W. A highly sensitive non-enzymatic glucose sensor based on copper oxide nanoparticlesmodified carbon nanotubes electrode. Biosensors and Bioelectronics, 2010; 25:1402-1407.

[21] Kaldova, R. and Kopanica, M. Tuning the reactivity of metal held in a rigid ligand environment. Pure and Applied Chemistry, 1989; 61:1681-1694.

[22] Khatib E. and Hameed R.Development of cuprous oxide / carbon vulcan xcarbon-72 as non-enzymatic sensor for glucose determination. Biosensors and Bioelectronics, 2011; 26:3542-3548.

[23] Largeaud, F., Kokoh, K.B., Beden, B. and Lamy, C. On the electrochemical reactivity of anomers: Electrocatalytic oxidation of $\alpha$ - and $\beta$-d-glucose on platinum electrodes in acid and basic media. Journal of Electroanalytical Chemistry, 1995; 397:261-269.

[24] Li, C., Su Y., Zhang, S.W., Lv, Y., Xia, L. and Wang Y. An improved sensitivity nonenzymatic glucose biosensor based on a copperous oxide modified electrode. Biosensors and Bioelectronics, 2010; 26:903-907.

[25] Li, J. and Lin, X. Glucose biosensor based on immobilization of glucose oxidase in poly (o-aminophenol) film on polypyrrole-platinum nanocomposite modified glassy carbon electrode. Biosensors and Bioelectronics, 2007; 22:2898-2905.

[26] Li, J., Yuan, R., Chai,Q., Che, X., Li, W. and Zhong, X. Nonenzymatic glucose sensor based on a glassy carbon electrode modified with chains of platinum hollow nanoparticles and porous gold nanoparticles in a chitosan membrane. Microchim Acta, 2011; 172:163-169.

[27] Li, X.H., Xie, Z.H., Min, H., Xian, Y.Z., and Jin, L.T. Amperometric biosensor based on immobilization acetyleholinesterase on manganese porphyrin nanoparticles for detection of trichlorfon with flow-injection analysis system. Electrochemical analysis, 2007; 19:2551-2557.

[28] Liu, J. and Wang, J. A novel improved design for the firstgeneration glucose biosensor. Food Technol Biotechnol, $2001 ; 39: 55-58$.

[29] Loeb, W. Sugar decomposition iii. Electrolysis of dextrose. Biochemische. Zeitschrift Biochemistry Z, 1909; 17:132-144.

[30] Luna, A., Mele, M. and Arvia, A. J. The electro-oxidation of glucose on microcolumnar gold electrodes in different neutral solutions. Journal of Electro analytical chemistry, 1992; 323:149-162.

[31] Luo, Z.J, Yin, S., Wang, K., Li, H.M., Wang, L.G., Xu, H. and Xia, J.X. Synthesis of one-dimensional beta-nikel hydroxide nanostructure and their application as non-enzymatic glucose sensors. Material Chemistry of Physics, 2012; 132:387-394.

[32] Mansouri, S. and Schultz, J.S. A miniature optical glucose sensor based on affinity binding. National Biotechnology, $1984 ; 2: 885-890$.

[33] Miwa,Y., Nishizawa, M., Matsue, T. and Uchida, I. A conductometric glucose sensor based on a twin-microband electrode coated with a polyaniline thin film. Bull Chemistry Socsociety Japan, 1994; 67:2864-2866.

[34] Morikawa, M., Kimizuka, N., Yoshihara. M. and Endo, T. New colorimetric detection of glucose by means of electron-accepting indicators: ligand substitution of [Fe(acac)3-n(phen)n]n+complexes triggered by electron transfer from glucose oxidase. Chemistry of Europeans Journal, 2002; 8:5580-5584.

[35] Novoselov, S., Geim A., Morozov, V., Jiang, D., Zhang, Y., Dubonos, S., Grigorieva, V. and Firsov, A. Electric field effect in atomically thin carbon films. Science, 2004; 306:666-669.

[36] Park, S., Boo, H and Chung T. Electrochemical non-enzymatic glucose sensors. Analytical Chemistry Acta, 2006; 556:46-57.

[37] Park, S., Jeon, A., Boo, K., Park, J., Kim, H. and Chung, T. Non-enzymatic continuous glucose monitoring in human whole blood using electrified nanoporous platinum. Biosensor and Bioelectronics, 2012 31:284-291.

[38] Pickup, J.C., Hussain, F., Evans, N.D., Rolinski, O.J. and Birch, D.J. Fluorescence-based glucose sensors. Biosensors and Bioelectron, 2005; 20:2555-2565.

[39] Pletcher, D. Electrocatalysis: present and future. Journal of Applied Electrochemistry, 1984; 14:403-415. 
[40] Qiao N. and Zheng, J. Nonenzymatic glucose sensor based on glassy carbon electrode modified with a nanocomposite composed of nickel hydroxide and graphene. Microchim Acta, 2012; 177:103-109.

[41] Sattar, M.A. and Conway, B.E. Electrochemistry of the nickel oxide electrode-vi. Surface oxidation of nickel anodes in alkaline solution. Electrochimica Acta, 1969; 14:705-710.

[42] Shim J., Jang, K., Lee, C.and Lee, Y. Applications of porous platinum-filled micropore electrode: Direct amperometric glucose detection and potentiometric pH sensing. Electroanalysis, 2012; 23:2063-2069.

[43] Songa, E.A., Somerset, V.S., Waryo, T., Baker, P.G. and Iwuoha, E.I. Amperometric nanobiosensor for quantitative determination of glyphosate and glufosinate residues in corn samples. Pure Applied Chemistry, 2009; 81:123139.

[44] Srinivasan, C. Graphene - mother of all graphitic materials. Current Science, 2007; 92:1338-1339.

[45] Stankovich, S., Dikin, d. A., Piner, R. D., Kohlhaas, K. A., Kleinhammes, A., Jia, Y., Wu, Y. and Nguyen, S. Synthesis of graphene oxide based nanosheets via chemical reduction of exfoliated graphite oxide. Carbon, 2007; 45:1558-1565.

[46] Steiner, M., Duerkop, A. and Wolfbeis, O. Optical methods for sensing glucose. Chemistry Society Review, 2011; 40:4805-4839.

[47] Sukirtha, T.H. and Usharani, M.V. Gas chromatography-mass spectrometry organophosphate pesticide residues in water of the irrigation canals in

determination

the North Nadu/India. International Journal of Current Microbiology and

Applied Science, 2013; 2(8):321-329.

[48] Tang, F.Q., Meng, X.W., Chen, D., Ran, J.G. and Zheng, C.Q. Glucose biosensor enhanced by nanoparticles. Science China B, 2000; 43:268-274.

[49] Toghill, K.E. and Compton, R.G. Electrochemical non-enzymatic glucose sensors: A perspective and an evaluation. International Journal of Electrochemical Science, 2010; 5:1246-1301.

[50] Venugopal, N., Sumalatha, B., Bonthula, R.S. and Veeribabu.G. Spectrophotometric determination of organophosphate insecticide (chlorpyrifos) based on diazotisation with anthranilic acid. The Malaysian Journal of Analytical Sciences, 2012; 16(2):180 - 186.

[51] Wang, Y., Xu, H., Zhang, J. and Li, G. Electrochemical sensors for clinic analysis. Sensors, 2008; 8:2043-2081.

[52] Xia, Y., Huang,W., Zheng J.F., Niu, Z. and Li, Z. Nonenzymatic amperometric response of glucose on a nanoporous gold film electrode fabricated by a rapid and simple electrochemical method. Biosensors and Bioelectronics, $2011 ; 26: 3555-3561$.

[53] Xu, F.G, Cui, K., Sun, Y.J., Guo, C.L., Liu, Z.L., Zhang, Y., Shi, Y. and Li, Z. Facile synthesis of urchin-like gold submicro structures for nonenzymatic glucose sensing. Talanta, 2010; 82:1845-1852.

[54] Xu, L., Xia, J.X., Li H.M., Li, H.N., Wang, K. and Yin, S. Ionic liquid assisted solvothermal synthesis of copper polyhedron-pattern nanostructures and their application as enhanced nanoelectrocatalysts for glucose detection. Europeans Journal of Inorganic Chemistry, 2011; 9:1361-1365.

[55] Yang, J., Zhang D. and Gunasekaran, S. An amperometric non-enzymatic glucose sensor by electrodepositing copper nanocubes onto vertically well aligned multi-walled carbon nanotubes arrays. Biosensor and Bioelectronics, 2010; 26:279-284.

[56] Yeo, I. and Johnson, D. Anodic response of glucose at copper-based alloy electrodes. Journal of Electroanalytical Chemistry, 2000: 484:157-163.

[57] Zanello, P. 2003 Inorganic Electrochemistry. Theory, Practice and Application. The Royal Society of Chemistry. Cambridge, UK.

[58] Zhang, P., Zhang, L., Zhao, G.C. and Feng, F. A highly sensitive nonenzymatic glucose sensor based on CuO nanowires. Microchim Acta, 2012; 176:411-417.

[59] Zhao, C.Z., Shao, C.L., Li, M.H. and Jiao, K. Flow-injection analysis of glucose without enzyme based on electrocatalytic oxidation of glucose at a nickel electrode. Talanta, 2007; 71:1769-1773. 